\title{
EDUCAÇÃO INCLUSIVA: O TRABALHO PEDAGÓGICO COM ALUNOS PÚBLICO-ALVO DA EDUCAÇÃO ESPECIAL DO ENSINO FUNDAMENTAL II NA SALA DE AULA COMUM
}

\section{INCLUSIVE EDUCATION: PEDAGOGICAL WORK WITH STUDENTS WHO ARE THE TARGET-AUDIENCE OF SPECIAL EDUCATION IN REGULAR CLASSES OF PRIMARY SCHOOL II}

\author{
José Adnilton de Oliveira FERREIRA ${ }^{\mathrm{i}}$ \\ Relma Urel Carbone CARNEIRO ${ }^{\text {ii }}$
}

RESUMO: Este estudo discutiu como se dá o trabalho pedagógico com alunos públicoalvo da educação especial (PAEE) em sala de aula comum no processo de inclusão escolar em uma escola da rede privada de Araraquara SP, que atende alunos do ensino fundamental II. Realizou-se uma pesquisa de campo com uma abordagem de estudo de caso, a partir da seguinte questão problema: Como se dá o trabalho pedagógico com alunos (PAEE) em sala de aula comum no processo de inclusão escolar? O lócus da pesquisa foi uma Escola particular, que oferta anos finais do ensino fundamental. Para a coleta dos dados foram realizados questionários com perguntas abertas e fechadas. Os participantes da referida pesquisa foram (07) professores (as) do ensino fundamental II e a coordenadora pedagógica. Os dados coletados foram analisados a partir da definição inicial das seguintes categorias: trabalho pedagógico e inclusão escolar, assim como outras categorias de análise que emergiram do referencial teórico adotado na pesquisa. Objetivou-se como resultado deste estudo trazer contribuições teóricas e práticas significativas para o trabalho pedagógico no processo de inclusão escolar dos alunos (PAEE) em sala de aula comum no ensino fundamental II.

PALAVRAS-CHAVE: Inclusão escolar. Trabalho pedagógico. Educação especial

ABSTRACT: This study discusses how is the pedagogical work with target group students in special education (EEAP) in common classroom in the school inclusion process in a private school in Araraquara SP, which serves elementary school students II. We conducted a field research with a case study approach, from the following question problem: How is the pedagogical work with students (EEAP) in common classroom in the school inclusion process? The locus of the research was a private school, which offer final years of elementary school. To collect the data were conducted questionnaires with open and closed questions. Participants of that study were (07) teachers (as) elementary II teaching and pedagogical coordinator. The collected data were analyzed from the initial setting of the following categories: pedagogical work and school inclusion, as well as other categories of analysis that emerged from the theoretical framework adopted in the research. The objective as a result of this study bring significant practical and theoretical contributions to the pedagogical work in the process of school inclusion of students (EEAP) in common classroom in elementary II school.

KEYWORDS: School inclusion. Pedagogical work. Special education. 


\section{Introdução}

A concepção de uma escola acolhedora para todos fundamenta-se, entre outros marcos, na Declaração Universal dos Direitos Humanos de 1948, especificamente no seu artigo $26^{\circ}$ incisos I e II que dispõe que todo ser humano tem direito à instrução, que a instrução será orientada no sentido do pleno desenvolvimento da personalidade humana e do fortalecimento do respeito pelos direitos humanos e pelas liberdades fundamentais. A partir desse período amplia-se o crescimento de movimentos sociais que lutam por uma sociedade mais democrática, fortalecendo as críticas ao modelo homogeneizador de educação escolar e às práticas de segregação e categorização de estudantes. Outro documento histórico que podemos considerar relevante que reforça a ideia de uma escola para todos é a Declaração Mundial de Educação para Todos, elaborada em Jomtien/1990, que chama a atenção dos países para os altos índices de crianças, adolescentes e jovens sem escolarização, tendo como objetivo promover as transformações nos sistemas de ensino para assegurar o acesso e a permanência de todos na escola.

Em continuidade a essa abordagem histórica e política, a Conferência Mundial de Necessidades Educativas Especiais: Acesso e Qualidade, realizada pela UNESCO em 1994, propõe aprofundar a discussão, problematizando os aspectos acerca da escola não acessível a todos os estudantes. A partir desta reflexão acerca das práticas educacionais que resultam na desigualdade social de diversos grupos, o documento Declaração de Salamanca e Linhas de Ação sobre Necessidades Educativas Especiais, resultante da conferência, proclama que as escolas comuns representam o meio mais eficaz para combater as atitudes discriminatórias, promovendo assim uma concepção de educação democrática que deve levar em consideração a diversidade, ou seja, deve contemplar as diferenças individuais e oferecer experiências de aprendizagem conforme as habilidades, interesses e potencialidades dos alunos.

A partir dessa necessidade de mudança, de repensar novas práticas educacionais, surge a intenção de se considerar um novo padrão de estudante, de professor, de currículo e de gestão de forma a contemplar os princípios de inclusão. Visto que as políticas educacionais brasileiras apontam nesta direção e novas proposições surgem para o contexto educacional a fim de se entender como realizar mudanças significativas no cotidiano escolar, a ideia de escola de qualidade para todos tem se ampliado. 
A inclusão em educação tem um objetivo intrínseco que é aceitar toda e qualquer diferença no contexto escolar e possibilitar a todos acesso ao conhecimento. A escola inclusiva parte de princípios distintos da proposta da integração, modelo vigente no final do século XX, por volta da década de 1970, em que observava-se um movimento de integração social dos indivíduos que apresentavam deficiências, cujo objetivo era inseri-los em ambientes escolares, o mais próximo possível daqueles oferecidos à pessoa sem deficiência, para estimular a aceitação da sociedade. Tal proposta pressupunha a normalização, posta em prática nas escolas regulares, em que se recebia o aluno com deficiência em classe separadas e dispendia-se esforços no sentido de modificá-lo para que se parecesse com as pessoas sem deficiência, sem a preocupação em realizar modificações na estrutura escolar para atendê-lo de forma equânime. Contrariamente, a inclusão educacional tem em vista a participação de todos os alunos, numa estrutura comum que considera as características, os interesses e os direitos de cada um, independentemente de suas condições.

Atualmente discute-se muito sobre educação inclusiva, buscando romper com o modelo educacional de integração do aluno com deficiência. Embora a escola inclusiva deva dar respostas a todos os alunos buscando atender suas mais variadas diferenças, temos no Brasil a definição de quem são os estudantes (PAEE) público-alvo da educação especial, clientela que por razões especificas pode requerer estruturas e recursos diferenciados e por isso têm direito ao atendimento educacional especializado (AEE). A Resolução CNE/CEB, nº 4/2009 no seu artigo 4º considera público-alvo do AEE:

I - Alunos com deficiência: aqueles que têm impedimentos de longo prazo de natureza física, intelectual, mental ou sensorial.

II - Alunos com transtornos globais do desenvolvimento: aqueles que apresentam um quadro de alterações no desenvolvimento neuropsicomotor, comprometimento nas relações sociais, na comunicação ou estereotipias motoras. Incluem-se nessa definição alunos com autismo clássico, síndrome de Asperger, síndrome de Rett, transtorno desintegrativo da infância (psicoses) e transtornos invasivos sem outra especificação.

III - Alunos com altas habilidades/superdotação: aqueles que apresentam um potencial elevado e grande envolvimento com as áreas do conhecimento humano, isoladas ou combinadas: intelectual, liderança, psicomotora, artes e criatividade. 
De acordo com Werneck (2000) o conceito de educação inclusiva surge em 1994 na Conferência Mundial sobre Educação Especial, resultando na Declaração de Salamanca, (UNESCO, 1994, p. 10) com o objetivo de fornecer diretrizes básicas para a formulação e reforma de políticas e sistemas educacionais de acordo com o movimento de inclusão social. Esta declaração é considerada um dos principais documentos que visam à inclusão social.

Mas para que tal processo se efetive é preciso que sejam identificadas as demandas que o aluno apresenta em sua interação no ambiente escolar, e proporcionarlhe as condições necessárias para sua aprendizagem. A Declaração de Salamanca (UNESCO, 1994, p. 10) deixa claro esse aspecto quando afirma que "todas as crianças [...] têm direito fundamental à educação e que a elas deve ser dada a oportunidade de obter e manter um nível aceitável de conhecimentos". No caso dos alunos com deficiência, transtornos globais do desenvolvimento e altas habilidades/superdotação, que são público-alvo da educação especial (PAEE) na perspectiva da educação inclusiva, a educação especial passa a integrar a proposta pedagógica da escola regular.

Segundo Werneck (2000), no Brasil a política de educação inclusiva se inicia em 2001, com mudanças nas Diretrizes Nacionais para a Educação Especial e no Plano nacional de Educação, que estabeleceram objetivos e metas necessárias para uma educação de qualidade que atenda a diversidade em uma escola inclusiva. Acompanhando o processo de mudança, as Diretrizes Nacionais para a Educação Especial na Educação Básica determinam que: Os sistemas de ensino devem matricular todos os alunos, cabendo às escolas organizarem-se para o atendimento aos educandos com necessidades especiais, assegurando as condições necessárias para uma educação de qualidade para todos (BRASIL, 2001, p. 13).

Assim, os sistemas de ensino precisam assegurar a acessibilidade aos educandos que apresentam necessidades educacionais especiais, desenvolvendo medidas que possibilitem a eliminação de barreiras na edificação, incluindo instalações, equipamentos, mobiliários e também nos transportes escolares, bem como barreira na comunicação, garantindo na escola os recursos humanos e materiais necessários.

A partir dessas premissas nos indagamos se os professores estão preparados para receber/trabalhar com os alunos PAEE. Deve-se pensar na formação e acompanhamento desse trabalho docente, perceber a necessidade do trabalho pedagógico na perspectiva da inclusão escolar. Esses questionamentos nos levaram a ir a campo para investigar como tem sido o trabalho pedagógico com alunos público-alvo da educação especial 
(PAEE) em sala de aula comum do ensino fundamental II no processo de inclusão escolar.

\section{Fundamentação teórica}

A Educação Especial inserida no processo de inclusão se caracteriza como modalidade de ensino que apresenta um conjunto de recursos e serviços educacionais especiais organizados para dar apoio suplementar e, em alguns casos, substituir os serviços educacionais comuns, de modo a garantir a educação formal dos educandos que apresentem necessidades educacionais (MAZZOTTA, 1996).

A prática da inclusão dos alunos PAEE em sala de aula comum deve ser subsidiada com o apoio do professor do AEE, com intuito de promover o aprendizado levando em consideração não somente a deficiência, mas suas potencialidades.

Cabe enfatizar, porém, que Educação Inclusiva não consiste apenas em matricular o aluno com deficiência em escola ou turma regular como um espaço de convivência para desenvolver sua 'socialização'. A inclusão escolar só é significativa se proporcionar o ingresso e permanência do aluno na escola com aproveitamento acadêmico, e isso só ocorrerá a partir da atenção às suas peculiaridades de aprendizagem e desenvolvimento. (PLETSCH e FONTES, 2006, p.12).

Ainscow (2004) sugere que a inclusão escolar deve ser ancorada em três aspectos inter-relacionados, a saber: a) a presença do aluno na escola, substituindo o isolamento do ambiente privado familiar pela sua inserção num espaço público de socialização e aprendizagem; b) a sua participação efetiva em todas as atividades escolares, a qual não depende apenas de 'estímulos' de colegas e professores, mas do oferecimento de condições de acessibilidade e adaptações curriculares que se façam necessárias; e c) a construção de conhecimentos, função primordial da escola, e meta a ser perseguida durante o processo de inclusão.

A educação inclusiva nasceu e vem se fortalecendo dentro de um ensino regular sedento pela melhoria da qualidade da escolarização, o que requer a aplicabilidade do que estabelece as leis acima mencionadas e a criação e efetivação de políticas públicas em nível dos governos municipais, estaduais e federal.

Nesse sentido, concebe-se a inclusão como processo educacional através do qual "todos os estudantes incluindo os com deficiência, são educados juntos, com o apoio 
necessário na idade adequada em instituições de ensino regular na vizinhança de suas casas" (WERNECK, 2000, p. 58). A escola ainda está fundamentada na hegemonia, na homogeneidade, e dessa forma a questão da aceitação e prática da diversidade ficam comprometidas, mostrando o preconceito devido à dificuldade que as pessoas têm em aceitar as diferenças dos outros. Esta afirmação nos leva a refletir na seguinte interrogação: estará o nosso professor (a) preparado e com disposição para trabalhar com alunos com essas características?

Partindo desta breve reflexão e da seguinte afirmação de Carmo (2000): "a inclusão é um assunto que deve ser refletida e investigada com muita precisão, já que a sociedade pode estar criando uma nova modalidade: a de excluídos dentro da inclusão.", podemos concluir nossa reflexão da seguinte maneira: para que aconteça o efetivo trabalho pedagógico no processo de ensino e aprendizagem dos alunos (PAEE), esse professor deve ter compromisso e consciência desse paradigma de educação inclusiva, devendo-se preparar em cursos de formação de professores repensando seus pressupostos epistemológicos, filosóficos e pedagógicos tanto na formação inicial quanto em serviço, e terá que tentar conciliar a teoria sobre o assunto com sua prática e a realidade da sala de aula.

Sendo assim, o trabalho pedagógico na sala de aula comum com alunos do PAEE deve pensar a inclusão escolar através de novas posturas tanto dos professores quanto do sistema educacional brasileiro, levando em consideração que todos nós estaremos ganhando. Lembrando também que este processo de aprendizagem requer a reciprocidade das experiências entre o aluno que é público-alvo da educação especial, o professor e os demais alunos. Um processo de aprendizagem onde todos participem.

O recorte para este estudo teve como propósito uma investigação do trabalho pedagógico com alunos (PAEE) em sala de aula comum no processo de inclusão do ensino fundamental II. O lócus da pesquisa foi uma escola particular pertencente ao sistema de ensino do município de Araraquara.

\section{Método}

\section{Contexto e definição do estudo}

Este estudo seguiu uma abordagem de pesquisa qualitativa. O problema e os 
objetivos propostos para a pesquisa levaram-nos a utilizar como procedimento metodológico o Estudo de Caso, por compreendermos que atende aos objetivos definidos neste estudo.

Na visão de (LUDKE e ANDRÉ, 1986, p. 17), o estudo de caso é sempre bem delimitado, devendo ter seus contornos claramente definidos no desenrolar do estudo. [...] $\mathrm{O}$ interesse incide naquilo que ele tem de único, de particular, mesmo que posteriormente venham a ficarem evidentes certas semelhanças com outros casos ou situações.

Desenvolvemos a pesquisa em uma escola privada de ensino fundamental localizada no município de Araraquara, no interior de São Paulo, que oferta o ensino fundamental-II e que tinha no momento da coleta de dados 250 alunos regularmente matriculados, sendo dois alunos (PAEE) diagnosticados da seguinte maneira: (01) um aluno com deficiência auditiva e (01) um aluno com deficiência intelectual. A escola atende majoritariamente alunos das classes média e média baixa.

Esse tipo de escola da rede privada vem se expandindo, sendo que esta rede investigada conta com 03 três unidades na cidade de Araraquara-SP, demonstrando na sua proposta pedagógica uma preocupação com o desenvolvimento do senso crítico e do espírito questionador de seus alunos, como fundamentos de uma atitude independente, responsável, inteligente, criativa, com espírito de iniciativa e perseverança como fatores determinantes na realização pessoal e profissional. A rede desenvolve seu método e material didático próprio, cuja eficiência tem sido comprovada em 50 anos de experiência. Os cadernos de atividades são elaborados por profissionais especializados nas diferentes áreas do conhecimento. No planejamento e na execução de cada atividade é levado em conta o nível de conhecimento dos alunos, o seu ritmo de aprendizagem e os tipos de motivação que os inspiram. Com a democratização do ensino, tais escolas tornaram-se uma alternativa às escolas públicas ou privadas de alto prestígio. Para as famílias menos favorecidas do ponto de vista econômico, essas instituições são consideradas de qualidade, diante do descrédito da escola pública e da impossibilidade de arcar com as altas mensalidades das escolas de elite, e com o objetivo de oportunizar uma educação de qualidade aos filhos, tais famílias delegam a esse tipo de instituição uma melhor formação que lhes assegure maior ascensão social.

O colégio investigado utiliza sistema apostilado de ensino, que inclui cadernos pedagógicos para professores e alunos, próprios para cada série dos segmentos dos ensinos fundamental e médio. A coordenadora pedagógica justifica a escolha pela 
necessidade de unificar o trabalho da rede e manter a escola no topo das avaliações externas, preservando, dessa forma, a qualidade do ensino, na sua visão.

\section{Participantes e Instrumentos de coleta de dados}

A seleção dos participantes foi realizada através do contato anterior com a coordenação pedagógica da escola, que relatou que no ensino fundamental-II havia um aluno com deficiência intelectual e outro aluno com deficiência auditiva na época do desenvolvimento da pesquisa, sendo esses dois 02 alunos do PAEE matriculados regularmente na sala de aula comum. Para a coleta dos dados foram aplicados dois questionários, um com questões abertas e fechadas exclusivamente para sete (07) professores do ensino fundamental-II, e outro para a coordenadora pedagógica, com o objetivo de verificar a prática pedagógica com alunos PAEE no cotidiano da sala de aula comum.

\section{Análise de dados}

A análise de dados dos questionários aplicados aos professores e à coordenadora pedagógica, in lócus, foi feita através de sintetização e tabulação das respostas e leitura detalhada de todo o material transcrito para identificação de categorias de análise.

\section{Resultados e discussão}

A apresentação dos resultados e discussão da pesquisa ocorrerá em dois níveis análise dos questionários aplicados aos professores e análise do questionário aplicado à coordenadora pedagógica. Quanto ao número de alunos, a referida escola tem um total de 250 alunos matriculados no Ensino Fundamental-II, sendo 02 dois alunos (PAEE) diagnosticados da seguinte maneira: (01) um aluno com deficiência auditiva e (01) um aluno com deficiência intelectual. A escola possuía uma sala de recursos que atendia 
esses dois alunos, ambos matriculados regularmente no $6^{\circ}$ ano do ensino fundamental-II e frequentando a sala de aula comum.

\section{Análise do questionário aplicado à coordenadora pedagógica.}

A aplicação do questionário à coordenadora pedagógica ocorreu anteriormente à aplicação dos questionários para os professores. e teve como objetivo averiguar o conhecimento da coordenação pedagógica a respeito da organização do processo de inclusão na escola. Para análise do questionário, foram considerados os seguintes itens: 01. Dados gerais da coordenadora pedagógica; 02. Discussão na sociedade sobre a inclusão escolar dos alunos (PAEE) público-alvo da educação especial na escola de ensino comum; 03. Concepção de educação inclusiva; 04. Atuação pedagógica; 05. Trabalho com a família.

A referida coordenadora tem licenciatura plena em Pedagogia com especialização em Coordenação Pedagógica, atua como coordenadora pedagógica da escola pesquisada, e seu tempo de atuação nesta escola é de 02 anos e 03 meses.

Com os dados das respostas da coordenadora pedagógica, algumas análises são possíveis. Partindo da questão 01, que versava sobre organização da comunidade escolar para a inclusão, a coordenadora afirma que a comunidade escolar não mostra-se organizada para desenvolver o processo inclusivo, enfatizando uma dicotomia com as questões 2 e 3, que tratavam da motivação na comunidade escolar para com o processo de inclusão escolar dos alunos PAEE e se os professores da escola mostravam-se organizados para inclusão escolar. A coordenadora relatou uma motivação mediana, ou seja, como pode ter motivação da comunidade escolar, que envolve principalmente os professores, se segundo a própria coordenadora não existe organização para o trabalho na sala de aula comum com a inclusão dos alunos especiais? Ela já tinha afirmado que essa própria comunidade escolar não se mostrava organizada para desenvolver esse trabalho inclusivo. Para entendermos este conceito (ROPOLI, 2010, p. 23) afirma que: A escola se torna inclusiva quando reconhece as diferenças e busca o progresso de todos, adotando novas práticas pedagógicas que dependem de mudanças que vão além da sala de aula, com o desenvolvimento de novos conceitos compatíveis com a inclusão. 
Em relação à concepção de educação inclusiva, a coordenadora entende esse processo como necessário, que é razoável nesse contexto de mudanças e desafios para a escola do século XXI em um sistema democrático. Ela se posiciona altamente favorável a inclusão escolar nas escolas privadas, mostrando que enfrentamos e teremos ainda pela frente muitos desafios em relação a esse processo de inclusão escolar com os alunos PAEE. Em consonância com a resposta da coordenadora, concordamos que há muito trabalho a ser feito, pois existe ainda muita resistência em relação a esse movimento de inclusão, vemos como necessário haver uma verdadeira metamorfose no modelo único de escola que temos, em virtude de que falta muito para que as escolas se tornem inclusivas, uma vez que estão alicerçadas em um modelo homogeneizador e consequentemente excludente.

Segundo autores como Pletsch e Fontes (2006), a meta de uma escola inclusiva ainda é um desafio, devido à sociedade não ter rompido com as barreiras do preconceito, da falta de informação e do medo. Para atender a todos. a escola atual precisa mudar, e essa tarefa exige trabalho em equipe. Cada escola, ao abraçar esse trabalho, terá que encontrar soluções próprias para os seus problemas.

As mudanças necessárias dependem de vontade política, administrativa e pedagógica, assumida pelo coletivo da escola, explicitada no seu Projeto Político Pedagógico (PPP) e vivida a partir de uma gestão escolar democrática.

A escola pesquisada possuía dois alunos com deficiência, auditiva e intelectual, ambos do $6^{\circ}$ ano do ensino fundamental-II, e embora tivesse uma sala de recursos não possuía um professor especializado para fazer o atendimento educacional especializado. A escola contava com um intérprete que acompanhava o aluno surdo na sala de aula comum e, segundo a coordenadora, muitas vezes ela assumia o papel do professor especializado, auxiliando no planejamento pedagógico dos professores que atuavam com esses alunos.

Da análise das respostas do questionário aplicado à coordenadora pedagógica pode-se depreender que, conforme seu relato, ainda existem muitas dúvidas sobre a importância do professor da educação especial na escola e principalmente a respeito das funções e atribuições do AEE. Essas dificuldades nesse entendimento acarreta a falta de acompanhamento pedagógico específico para os alunos com deficiência. Dessa forma, a coordenação pedagógica fica acumulando isoladamente o trabalho na sala de recursos e na responsabilidade de conduzir juntamente com os professores todo o processo educacional dos alunos PAEE. 
Pode-se dizer que existe a necessidade de se refletir sobre as práticas adotadas no trabalho pedagógico com alunos especiais em sala de aula comum nessa escola privada, e reafirmar a importância da sala de recursos com profissionais devidamente preparados para atender esses alunos como primordial para trabalhar no desenvolvimento psicológico, cognitivo, social, enfim, em todo o processo de ensino e aprendizagem dos mesmos.

Principalmente por entender a importância do AEE como implementação das ações educacionais inclusivas junto a alunos (PAEE), esse atendimento busca construir e utilizar ferramentas e procedimentos de ensino que desenvolva o trabalho pedagógico com esses alunos, possibilitando uma parceria que se constitua de fato como suporte ao ensino inclusivo.

Esse modelo de escola requer algumas mudanças, uma vez que a escola nem sempre consegue oferecer todos os recursos necessários para promover o sucesso de todos os alunos. Conforme Carneiro (2006):

A escolarização de alunos com deficiências, altas habilidades/superdotação e transtornos globais do desenvolvimento (PAEE), junto com seus pares na escola comum é um imperativo já garantido legalmente. Sua efetivação requer mudanças na estrutura escolar para atender especificidades até então desconhecidas pela comunidade escolar. Essas mudanças vão desde alteração na estrutura física, passando por alteração no mobiliário, nos processos de gestão, nos recursos pedagógicos, instrumentais e alteração no trabalho docente. A abertura da escola para os alunos acima citados, não extingue suas particularidades, de forma que o oferecimento de atendimento especializado muitas vezes se faz necessário. (CARNEIRO, 2006).

Os alunos PAEE muitas vezes necessitam de atendimento educacional especializado para dar respostas especificas às suas necessidades e de acordo com a Constituição Federal (BRASIL, 1988) e a LDB (BRASIL, 1996), esse atendimento deve ser oferecido preferencialmente na rede regular de ensino. Conforme a Política Nacional de Educação Especial na Perspectiva da Educação Inclusiva (BRASIL, 2007), esse atendimento deve ser oferecido no contra turno por professor especializado. Como vimos na escola pesquisada, este direito, que tem embasamento legal, nem sempre é garantido a quem de direito.

\section{Análise dos questionários aplicados aos professores}


A segunda parte da análise dos resultados e discussão da pesquisa, é dos questionários aplicados aos sete 07 professores do ensino fundamental-II, que aqui denominaremos de professor 01 a 07.

$\mathrm{Na}$ primeira questão, os professores foram inquiridos sobre o seguinte questionamento: Atualmente há uma acirrada discussão na sociedade sobre a inclusão escolar dos alunos (PAEE) na escola de ensino comum. Qual é a sua visão como professor (a) sobre essa discussão? Seis (06) professores responderam que concordam com a inclusão escolar, que ela é necessária independente da deficiência do aluno, mas consideram fundamentais os suportes de apoio, como as salas de recursos multifuncionais e da formação continuada pensada para o processo inclusivo, mas defendem a inclusão escolar dos alunos (PAEE) no ensino comum. Contrariamente, um (01) professor mostrou-se resistente à inclusão escolar desses alunos na escola de ensino comum, por entender que a deficiência é um obstáculo para incluir esse aluno (PAEE) no ensino comum. Essa postura nos leva a questionar a concepção de inclusão que esse professor tem, uma vez que a proposta inclusiva não se resume ao atendimento a alunos com deficiência, e sim, significa oferecer condições equânimes a todos os alunos para que tenham suas necessidades atendidas considerando suas especificidades, sejam elas quais forem. Felizmente esse posicionamento foi isolado, já que seis professores defendem a inclusão escolar dos alunos (PAEE) no ensino comum.

As respostas para a questão 2, que versava sobre a importância da aprendizagem escolar dos alunos (PAEE) e a frequência do planejamento pedagógico com o atendimento educacional especializado (AEE) estão dispostas no gráfico abaixo:

Gráfico 1 - Frequência do planejamento pedagógico com o (AEE).

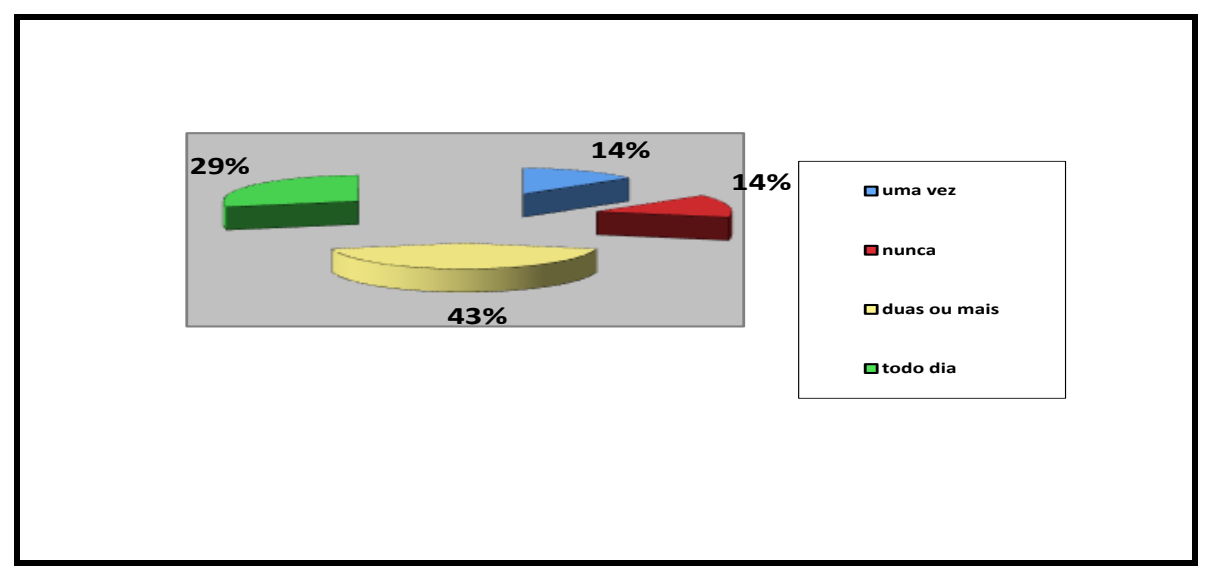

Fonte: Professores do ensino fundamental-II da escola pesquisada. 
Considerando o gráfico acima, segundo relato dos sete professores, quanto à frequência do planejamento pedagógico com o AEE, pode ser descrito da seguinte forma: Dois professores relataram que ocorre todo dia; um relatou que apenas uma vez, um disse que nunca houve e três explicitaram que o planejamento pedagógico com o atendimento educacional especializado ocorre duas ou mais vezes na semana. Observase um resultado contraditório dos professores quanto ao planejamento pedagógico, não ocorre uma unidade desse processo junto com o AEE, um professor relata que nunca houve esse planejamento e a maioria, no caso cinco (43\% e 29\%) professores, demonstraram que estão profundamente satisfeitos com esse acompanhamento pedagógico que deve ser visto como primordial para pensar na aprendizagem escolar.

O trabalho docente é uma ação de extrema complexidade. O trabalho docente em uma sala com um aluno PAEE requer um trabalho integrado com a coordenação pedagógica e o professor do atendimento educacional especializado - AEE, para o reconhecimento dessa complexidade e do acolhimento das diferenças individuais dos alunos (PAEE), como pontos de problematização para que se possa lidar com a ideia e a proposta inclusiva de forma abrangente. Deve-se pensar na formação inicial e em serviço, nas assessorias e acompanhamento pedagógico do trabalho docente, principalmente para o professor que trabalha com alunos (PAEE) em sala de aula comum, aspectos fundamentais ao pensarmos o trabalho docente na perspectiva da inclusão escolar.

Na sequência, apresentamos os dados da questão 3, que discorreu sobre o papel da interação entre alunos PAEE e alunos considerados "normais", como relevante para aquisição de conhecimentos e habilidades por parte dos alunos. O Professor 01 descreveu assim: “Até certa idade eles são amigos, depois eles vão se afastando". Para o Professor 02 "Depende, os alunos normais aceitam a integração até certa idade, depois restringe para um ou outro colega". O Professor 03 disse: "A interação é importante, mas devemos criar mecanismos para que o aluno (PAEE) consiga acompanhar a turma". Os professores 04, 05, 06 e 07 fizeram seus relatos com certas aproximações de respostas, concordando com a interação como propulsor do desenvolvimento cognitivo, psicológico, físico, mas principalmente como elemento de socialização, possibilitando a aprendizagem na coletividade.

Podemos entender que quatro professores relatam de forma positiva a interação dos alunos considerados "normais" com os alunos (PAEE), conseguindo entender/compreender a interação desses alunos como reais possibilidades de avanços 
cognitivos e físicos para esses alunos especiais. Convivendo no mesmo ambiente escolar facilita-se as etapas do processo de ensino-aprendizagem, pois os alunos que possuem algum tipo de deficiência, sejam sensoriais, físicas, intelectuais, etc, sempre se beneficiam dessa convivência. Essa criança irá interagir e tentará superar suas limitações. Isso não seria possível, por exemplo, se ela estudasse numa escola só de crianças que também possuíssem a mesma deficiência. Devemos reconhecer a importância da escola e as interações entre os diferentes alunos no processo de desenvolvimento do aluno (PAEE) e as concepções sobre este assunto que justificam a importância dessa socialização/interação. Vale lembrar que os benefícios dessa inclusão são mútuos, uma vez que a valorização das diferenças no ambiente escolar promove a aprendizagem e o desenvolvimento de todos os alunos.

Por fim, das respostas fornecidas pelos sete professores da sala de aula comum inquiridos na pesquisa, podemos explicitar que as principais dificuldades no processo de inclusão escolar do aluno "especial" são causadas pela ausência de um preparo mais teórico-técnico-metodológico que vise suprir as lacunas na formação inicial e em serviço, não somente do professor, mas de todos os profissionais envolvidos no processo de inclusão escolar dos alunos PAEE. Podemos considerar também como dificuldade a falta de boas condições estruturais e materiais na escola para receber estes alunos. Podemos afirmar a partir das respostas desses professores que a interação do aluno (PAEE) com os demais alunos na sala de aula comum tem como consequência uma melhor constituição dos valores humanos de todos os alunos e trocas de experiências profícuas entre os alunos considerados "normais" e o aluno "especial". Essa manifestação também contribui na superação dos obstáculos encontrados durante o processo de aprendizagem.

Os professores intensificaram a ideia de que eles não estão ainda preparados para enfrentar esse novo desafio. Ficou evidente que é necessário reavaliar a formação do professor sobre esse enfoque de incluir o aluno "especial" no ensino comum. Essa realidade denuncia os aspectos dissonantes dessa prática pedagógica, que reflete a necessidade urgente de formação em serviço para esses profissionais, dos sistemas de ensino assegurarem acessibilidade e aprendizagem aos alunos (PAEE), desenvolvendo medidas que possibilitem a eliminação de barreiras na edificação, incluindo instalações, equipamentos, mobiliários e também nos transportes escolares, bem como barreira na comunicação, garantindo na escola recursos humanos e materiais necessários para uma educação de qualidade. 
Quanto ao trabalho pedagógico na escola investigada com alunos PAEE em sala de aula comum, ficou evidente a improvisação pedagógica, ou seja, deixar fazer e acontecer, sem nenhum direcionamento das atividades didático-pedagógicas para esses alunos, fato esse que ocorre principalmente pela inexistência do profissional e/ou trabalho do professor da educação especial na sala de recursos que estabeleça uma ligação junto ao professor da sala de aula comum.

Por último, no que diz respeito ao trabalho com a família, não ficou evidenciado nenhuma interação da escola com as famílias, embora a coordenadora pedagógica tenha relatado que considera importante a participação da família junto à escola, porém afirma que os pais não fazem o acompanhamento das dificuldades que seus filhos apresentam. Assim, percebe-se, na realidade investigada, um distanciamento da relação pais-escola da perspectiva de ensino inclusivo, a qual é dada pelas Diretrizes Nacionais como a construção de uma rede de apoio em que a família participe efetivamente do processo educacional de seus filhos.

\section{Conclusões}

O estudo buscou investigar como se dá o trabalho pedagógico com alunos público-alvo da educação especial (PAEE) a saber, alunos com deficiência, transtornos globais do desenvolvimento e altas habilidades/superdotação, na sala de aula comum no processo de inclusão escolar em uma escola da rede privada de Araraquara, no interior de São Paulo.

Dentro do conjunto de dados analisados - o questionário aplicado à coordenadora pedagógica e aos professores, verificamos inúmeras discrepâncias entre o que se estabelece em termos legais e a realidade escolar. Se, por um lado, no contexto investigado, são cumpridos alguns aspectos formais da legislação, por outro, ficam questionamentos quanto ao fato de que a sala de recursos se constitui como suporte ao ensino inclusivo. O papel da sala de recursos não é desempenhado na sua íntegra, em virtude principalmente de não existir o professor da educação especial que tenha formação para realizar o atendimento educacional especializado. De uma maneira geral, os resultados indicam que há uma nítida descaracterização da sala de recursos como um suporte ao ensino inclusivo, cuja função é garantir o atendimento complementar ou suplementar aos alunos que dela necessitem para acessar o currículo comum. Ou seja, 
esse serviço se cumpre de forma contrária as determinações legais e a sua efetivação como suporte no contexto de ensino inclusivo é questionável. Por se tratar de um estudo de caso, este trabalho não permite generalização dos dados e, para tanto, outras pesquisas são necessárias para aprofundamento da temática.

Para finalizar, cabe pontuar que a inclusão escolar requer uma nova dimensão paradigmática de escola, verdadeiramente humanizadora, que valorize a diversidade e caminhe para transformar-se em uma instituição educacional genuinamente para todos.

\section{Referências}

ALVES-MAZZOTTI, A. J.; GEWANDSZNAJDE, F. O método nas ciências naturais e sociais: pesquisa quantitativa e qualitativa. 2. ed. São Paulo: Pioneira, 2002.

AINSCOW, M. $O$ que significa inclusão? Disponível em:〈http://www.crmariocovas.sp.gov.br/ees_a.php?t=002>. Acesso em: 24 jul. 2004.

BARDIN, L. Análise de conteúdo. 70. ed. Lisboa: Casagraf - artes gráficas Unipessoal, 2002.

BRASIL. Declaração Mundial sobre Educação para Todos: plano de ação para satisfazer as necessidades básicas de aprendizagem. UNESCO, Jomtiem/Tailândia, 1990.

Declaração de Salamanca e linha de ação sobre necessidades educativas especiais. Brasília: UNESCO, 1994.

Ministério da educação: Diretrizes nacionais para a Educação Especial na Educação Básica. Secretaria de Educação Especial. MEC. SEESP, 2001.

Comitê Nacional de Educação em Direitos Humanos. Plano Nacional de Educação em Direitos Humanos. Brasília: Secretaria Especial dos Direitos Humanos, Ministério da Educação, Ministério da Justiça, UNESCO, 2006.

fev. 2014

Constituição Federal de 1988. Disponível em <mec.gov.br〉. Acesso: 19 de

Resolução CNE/CEB $n^{\circ}$ 4, de 2 de outubro de 2009. Institui. Diretrizes Operacionais para o Atendimento Educacional Especializado na Educação Básica, modalidade Educação Especial. Disponível em: <http://peei.mec.gov.br/arquivos/Resol_4_2009_CNE_CEB.pdf >. Acesso em: $10 \mathrm{dez}$. 2014.

Lei $\mathbf{n}^{\mathbf{0}}$ 9394, de 20 de dezembro de 1996. Disponível em<http://www.planalto.gov.

br/ccivil_03/LEIS/L9394.htm>. Acesso em: 06 de out. de 2014. 
CARNEIRO R. U. C. Formação em serviço sobre gestão de escolas inclusivas para diretores de escolas de educação infantil. 2006. 174 f.Tese (Doutorado em Educação Especial) Programa de Pós-Graduação em Educação Especial: UFSCar, São Carlos, 2006.

LUDKE, M.; ANDRÉ, M. E. D. A. Pesquisa em educação: abordagens qualitativas. São Paulo: EPU, 1986.

MAZZOTTA, M. J. S. Educação Especial no Brasil: História e políticas públicas. São Paulo: Cortez, 1996.

ONU. Declaração Universal dos Direitos Humanos. 1948. Disponível em. <Http://www.onu-brasil.org.br/documentos_direitoshu manos.php>. Acesso em: $19 \mathrm{de}$ ago. de 2015.

PLETSCH, M. D; FONTES, R. de S. A inclusão escolar de alunos com necessidades Especiais: diretrizes, práticas e resultados de uma experiência brasileira. Revista Educar, Jalisco, México, n. 37, p. 87-97, 2006.

ROPOLI, E. A. A Educação Especial na Perspectiva da Inclusão Escolar: a escola comum inclusiva. Brasília: Ministério da Educação, Secretaria de Educação Especial, 2010.

WERNECK, Claudia. Ninguém mais vai ser bonzinho na sociedade inclusiva. 2 ed. Rio de Janeiro: WVA, 2000.

\section{Como referenciar este artigo}

FERREIRA, José Adnilton de Oliveira.; CARNEIRO, Relma Urel Carbone. Educação inclusiva: o trabalho pedagógico com alunos público-alvo da educação especial do ensino fundamental II na sala de aula comum. Revista Ibero-Americana de Estudos em Educação, v. 11, n. esp. 2, p.969-985, 2016. Disponível em: <https://dx.doi.org/10.21723/riaee.v11.esp2.p969-985>. E-ISSN: 1982-5587.

${ }^{\text {i }}$ Mestrando em Educação Escolar UNESP - Universidade Estadual Paulista. Faculdade de Ciências e Letras - Pós-graduação em Educação Escolar. Araraquara - SP - Brasil. 14800-901 joseadnilton_ap@yahoo.com.br

ii UNESP - Universidade Estadual Paulista. Faculdade de Ciências e Letras - Pós-graduação em Educação Escolar. Araraquara - SP - Brasil. 14800-901 - relmaurel@ fclar.unesp.br 